\title{
Treatment of Morbid Obesity: Intensive Lifestyle Intervention vs. Bariatric Surgery
}

Thomas Bächler ${ }^{1}$, Dimitris Papamargaritis ${ }^{2}$, Marco Bueter ${ }^{1}$ and Carel W le Roux ${ }^{3 *}$

${ }^{1}$ Department of Surgery, Division of Visceral and Transplantation Surgery, University Hospital Zürich, Zürich, Switzerland

${ }^{2}$ Department of Diabetes and Endocrinology, Leicester Royal Infirmary Hospital, Leicester, UK

${ }^{3}$ Experimental Pathology, Conway Institute, School of Medicine and Medical Sciences, University College Dublin, Dublin, Ireland

\begin{abstract}
Obesity has reached an epidemic dimension composing a serious threat to health systems worldwide. It has been associated with numerous comorbidities including cardiovascular disease, type 2 diabetes mellitus, cancer, nonalcoholic fatty liver disease, arthritis, infertility, eating disorders, unemployment and a reduced quality of life. Bariatric surgery is currently the only effective treatment for severe obesity. Non-surgical treatment modalities include lifestyle changes, diet and/or exercise, with pharmacotherapy and less invasive medical devices. This article therefore aims to discuss the available therapy options including surgical and non-surgical treatments as well as to compare both modalities regarding their clinical effectiveness.
\end{abstract}

Keywords: Obesity; Health problem; Causes of obesity

\section{Introduction}

Obesity is an increasingly prevalent worldwide health problem. The prevalence of the disorder in adults has more than tripled in the past decade, and obesity currently affects approximately $20-35 \%$ of the general population in the developed world [1]. Obesity is a major contributor to some of the leading causes of death in the developed world, including heart disease, stroke, diabetes and some types of cancer [2]. Specific causes of obesity are still unclear, but it is likely that a combination of metabolic, genetic, psychological, and environmental factors all contribute to the obesity epidemic [3]. Multiple studies have been performed the last years in the area of obesity and have provided a variety of options for treatment of obesity and its related comorbidities. Treatment options can be separated into non- surgical and surgical interventions, i.e, Lifestyle, diet and/or exercise, with pharmacotherapy and less invasive medical devices compared to operations such as Rouxen-Y bypass, sleeve gastrectomy and gastric banding.

The aim of this paper will be to discuss the available treatment options and their effect on all the components of morbid obesity as categorised by the King's Obesity Staging Iscore [4,5]. Levels of evidence are given where appropriate according to the Oxford Centre for Evidence-based Medicine Levels of Evidence (www.cebm.net).

\section{Non-Surgical interventions}

\section{Airway}

In the Look AHEAD study, the patients were randomized to an Intensive Lifestyle Intervention (ILI) or to a Diabetes Support and Education Program (DSE) [6]. Among obese adults with type 2 diabetes and obstructive sleep apnoea, ILI produced greater reductions in weight and apnea-hypopnea index over a 4 year period than the DSE (Evidence level 1b). Beneficial effects of ILI on apnea hypopnea index at 1 year persisted at 4 years, despite an almost $50 \%$ weight regain. Effect of ILI on apnea-hypopnea index was largely, but not entirely, due to weight loss. Change in apnea-hypopnea index over time was related to the amount of weight loss while remission of OSA at 4 years was 5 times more common with ILI (20.7\%) than DSE (3.6\%) [7].

\section{Body mass index (BMI)}

During the Look AHEAD study the mean weight loss in the ILI at the end of the first year was $8.6 \%$ (Evidence level $1 \mathrm{~b}$ ). This was followed by weight regain through year five and then a subsequent gradual decrease in weight, resulting in an average weight loss of $6.0 \%$ after 9.6 years. The DSE (control) group lost a total of 3.5\% weight gradually throughout the study [8].

Adding pharmacotherapy to ILI add another $2-3 \mathrm{~kg}$ weight loss [9] while medical devices such as the duodenal jejunal bypass can lead to $15-20 \%$ weight loss after 1 year $[10,11]$. However, long-term results after the removal are not yet available.

\section{Cardiovascular disease (CVD)}

Patients in the ILI of the Look AHEAD study, lost more weight, improved their cardiovascular fitness, had lower HbA1C, lower systolic and diastolic blood pressure, elevated high-density lipoprotein cholesterol, and lower triglycerides, but despite all the improvements in there was no difference in cardiovascular morbidity and mortality, even in overweight or obese adults with type 2 diabetes $[8,12]$. The SCOUT study also showed that intentional weight loss with sibutramine lowered body mass index, but did not reduce mortality.

\section{Diabetes}

In Look AHEAD, the ILI group was significantly more likely to experience partial or complete remission (11.5\% during the first year and $7.3 \%$ at year 4 , compared with $2.0 \%$ for the DSE group at both time points) [13] (Evidence level 1b). Medication such as GLP-1 analogues reduce weight by $3-6 \%$ while also increasing postprandial insulin and thus reducing $\mathrm{HbAlc}$ by $\sim 1 \%[14,15]$. Regarding the available devices, the duodenal jejunal bypass seems to have an impressive effect on $\mathrm{HbA1C}$ with absolute reductions of $\sim 2 \%[16,17]$

\section{Economical}

Look AHEAD found that the ILI group reduce the use of

*Corresponding author: Carel le Roux, Experimental Pathology Conway Institute School of Medicine and Medical Sciences, University College Dublin, Belfield, Dublin 4, Ireland, E-mail: c.leroux@imperial.ac.uk

Received July 01, 2013; Accepted September 26, 2013; Published October 04 2013

Citation: Bächler T, Papamargaritis D, Bueter M, le Roux CW (2013) Treatment of Morbid Obesity: Intensive Lifestyle Intervention vs. Bariatric Surgery. Surgery Curr Res 3: 147. doi:10.4172/2161-1076.1000147

Copyright: $\odot 2013$ Bächler T, et al. This is an open-access article distributed under the terms of the Creative Commons Attribution License, which permits unrestricted use, distribution, and reproduction in any medium, provided the original author and source are credited. 
medications cost related with cardiovascular risk protection compared to the DSE group from US $\$ 173$ to $\$ 143$ per month [18] (Evidence level $1 b)$.

\section{Functional (physical activity)}

In Look AHEAD the ILI reduced severe disability and increased good mobility after 4 years [19]. In a subgroup of patients the ILI improved the Western Ontario and McMaster Universities Osteoarthritis Index (WOMAC) with reduced pain, stiffness, and improved physical function [20] (Evidence level 1b).

\section{Gonadal}

A subgroup of participants in the Look AHEAD study was assessed before and 1 year after intervention. The ILI group had improved erectile function in men [21]. The Female Sexual Function Inventory (FSFI) showed improvements in the ILI and allowed more women with Female Sexual Dysfunction (FSD) to remain sexually active [22] (Evidence level $1 \mathrm{~b}$ ).

\section{Health status perceived}

The Beck Depression Inventory (BDI) improved in patients in the ILI in the Look AHEAD study [23] (Evidence level 1b). The 36-Item Short-Form Health Survey Physical Component Summary (PCS) and the Mental Health Component Summary (MCS) scores also improved after ILI [24].

\section{Body image}

The ILI group had improvements of the body morph assessment version 2.0 (BMA 2.0) to assess perceived current body size, ideal body size, acceptable body size, and body image dissatisfaction at baseline and 1 year [25] (Evidence level 1b).

\section{Junction of gastro-oesophagus}

A recent systematic review identified seven studies that have evaluated the effect of the lifestyle or diet intervention on GastroOesphageal Reflux Disease (GORD) [26]. Two studies used a very lowcalorie liquid diet, one a low-calorie diet, one a very low carbohydrate diet and three, lifestyle interventions. Austin et al. showed an improvement in reflux symptoms and a reduction in acid exposure to the oesophagus with a low carbohydrate diet despite that significant weight loss was achieved [27] (Evidence level 3a). On the other hand, other studies found no improvement in reflux symptoms and pHmetry outcomes following dietary and lifestyle interventions $[28,29]$.

\section{Kidney}

A multidisciplinary programme combining diet, exercise and orlistat suggests that significant weight loss and improved physical functioning can be achieved in patients who are obese and have chronic kidney disease, increasing the number that became eligible for kidney transplantation [30].

\section{Liver}

In the Look Ahead study completed proton magnetic resonance spectroscopy showed reduced hepatic steatosis in an incident NAFLD in the ILI [31] (Evidence level 1b).

\section{Medications}

In the look AHEAD study, the medications prescribed to ILI group to treat diabetes, hypertension, and hyperlipidaemia were reduced compared with the DSE group at 1 and 9.6 years after intervention $[18,32]$ (Evidence level 1b).

\section{Surgical Interventions}

The most common bariatric procedures are Roux-en- $Y$ gastric bypass (RYGB), Gastric banding (GB) and Sleeve Gastrectomy (SG) [33]. The complications of bariatric surgery are being reduced by good surgical practice in specialist centres and the overall risk of death and other adverse outcomes are low. The Longitudinal Assessment of Bariatric Surgery-1 (LABS-1) study including 4431 bariatric procedures reported a 30 -day mortality rate of $0.3 \%$. Main causes of death were pulmonary embolism, cardiac events and anastomotic leakages [34]. The incidence of early perioperative complications after bariatric surgery is 7.3\% [35]. Rates of potentially life-threatening complications such as anastomotic leakages, obstruction and hemorrhage are considerably higher among patients undergoing RYGB $(3.1 \%)$ or SG $(2.2 \%)$ than after GB (0.8\%) [35]. Significant risk factors for surgical complications include a $\mathrm{BMI}>50 \mathrm{~kg} / \mathrm{m}^{2}$, male gender, hypertension, age $>45$ years and a known medical history of thromboembolism [36]. The incidence of venous thromboembolism or medical complications with cardiac, renal or respiratory failure has been reported to be highest in RYGB patients [35]. Late gastrointestinal complications including dumping syndrome with concomitant hypoglycemia, symptomatic cholelithiasis or gastroesophageal reflux disease and deficiency of micronutrients make long- term follow up of bariatric patients mandatory [37].

\section{Airway}

The Apnea- Hypopnea Index (AHI) is improved after surgical induced weight loss, but in most patients moderately to severe OSAS persists [38] (Evidence level 3a). However, 66\% of asthmatics undergoing bariatric procedures show a complete resolution after substantial weight loss [39].

\section{Body mass index}

The average body weight loss after surgery varies from $15 \%$ to $35 \%$ depending on the procedure used [33] (Evidence level 2a). Body weight reaches its nadir usually one to two years after bariatric procedures and increases afterwards [40]. The prospective, controlled Swedish Obese Subject (SOS) Study reported that after 10 years body weight reduction was $25 \%$ after RYGB and $13 \%$ after GB [40]. Randomized controlled trials (RCT) comparing weight loss after RYGB and SG reported heterogeneous results, but differences between the two procedures seem to be minor [41-43].

\section{Cardiovascular disease}

The Swedish Obese Subjects (SOS) study demonstrated improvements in T2DM, triglyceride and diastolic blood pressure 10 years after bariatric surgery, but no effect for systolic blood pressure and low density lipoprotein levels [44]. Improvement of the risk profile for cardiovascular disease delays the progression of atherosclerosis by the threefold in patients undergoing bariatric procedures [45]. The nonrandomized evidence suggests that obese patients treated by metabolic surgery have mortality benefit when compared to non-surgically treated control group [40] (Evidence level 2a). The lower mortality in the non- randomized surgical group seems to be mainly due to a reduced incidence of cardiovascular deaths and cancer in comparison to the control group [46].

\section{Diabetes (T2DM)}

Randomized controlled trials have shown RYGB to be an effective treatment for hyperglycemia in T2DM [47, 48] (Evidence level 1a). Until recently, there was no definition for the remission of diabetes, but the impressive effects of surgery led the American Diabetes Association (ADA) to create criteria for remission of diabetes [49]. 
Partial remission is defined as $\mathrm{HbA1C}$ levels below $6.5 \%$ and fasting glucose levels between 100 and $125 \mathrm{mg} / \mathrm{dl}$ [5.6-6.9 mmol/l]) for at least 1 year in the absence of any active pharmacologic therapy or ongoing procedures [32]. Complete remission can be diagnosed when $\mathrm{HbA1C}$ levels are $<6 \%$ with a fasting glucose below $100 \mathrm{mg} / \mathrm{dl}[5.6 \mathrm{mmol} / \mathrm{l}])$ for at least 1 year in the absence of any active pharmacologic therapy or ongoing procedures. After RYGB $41-57 \%$ of patients have remission of T2DM after 1 year $[32,50,51]$.

\section{Economic}

Surgery is not more expensive than medical care [52,53]. Recent data indicate that the costs related to a higher number of medical consultations in the first years after bariatric surgery are balanced by the higher drug costs in the non-surgical group during follow up [54]. Health related quality of life after RYGB improves significantly more than nonsurgical care [30,55] (Evidence level 3a).

\section{Functional}

Severe obesity is major risk factor for osteoarthritis [56] and is associated with musculoskeletal pain [57]. Hence, obesity significantly restricts activities of daily living such as walking and climbing stairs [58]. In contrast, work-restricting pain in the neck, back or knees has been reported to improve or even resolve after bariatric surgery [57]. The amelioration in vitality, physical functioning and body pain (Evidence level 3a) are well reflected by the improvement in the physical components of the short form health survey (SF-36) after bariatric operations [55].

\section{Gonadal}

Incidence of subfertility (41.9\%) and polycystic ovary syndrome (13.1\%) among women undergoing bariatric surgery is consistently higher than in the general population [59].The younger in age, the higher the risk for gonadal dysfunction [59].There is increasing evidence that bariatric surgery regularizes menstrual cycles and improves fertility in young women [60] (Evidence level 3b).

\section{Health status perceived}

Severe obesity is associated with multiple forms of negative health impact that affects quality of life. It has been suggested that $25 \%-30 \%$ of patients suffer from marked clinical symptoms of depression before surgery [58]. In the SOS study, health perceptions improved by $11 \%$ ten years after surgery [61]. There was also a substantial reduction of anxiety symptoms (23\%) ten years after bariatric surgery [61]. Furthermore, depression scores significantly improved, while the prevalence remained higher when compared to the population norm. Overall, positive effects of bariatric surgery on health-related quality of life (HRQL) seem closely connected to the amount of weight lost and data suggest that maintained weight loss of $10 \%$ is sufficient for positive long-term effects on HRQL [61] (Evidence level 2a).

\section{Body image}

Major body disturbance is common in severe obesity and affects social interaction [62]. Additionally many eating disorders, which are often present in patients applying for bariatric surgery, come along with an altered self perception. Binge eating disorder depending on definitions is present in $10-25 \%$ of candidates for surgery [58]. While body satisfaction after bariatric surgery improves dramatically [63] (Evidence level 3a), ability for social interaction remains impaired [61].

\section{Junctions of the gastro-oesophagus}

Obesity is a risk factor for Gastro-Oesophageal Reflux Disease
(GERD) and its complications, such as erosive oesophagitis and oesophageal adenocarcinoma [64]. While SG may induce or aggravate GERD [65], RYGB has been reported to be equally effective as a Nissen fundoplication for the treatment of GERD [66] (Evidence level 3b).

\section{Kidney}

Urine output and sodium excretion increase after RYGB surgery in rats [67] and humans [68] (Evidence level 3a). In addition, RYGB surgery is associated with an improvement in urinary and systemic inflammatory markers in patients [69]. A retrospective analysis in 83 patients with a BMI $>35 \mathrm{~kg} / \mathrm{m}^{2}$ and T2DM having RYGB or SG showed that both retinopathy grading and nephropathy markers, including urine Albumin Creatinine Ratio (ACR) improved significantly after surgery [70]. Mingrone et al. showed that not only did markers of kidney damage such as proteinuria improve 10 years after bariatric surgery, but kidney function as measured by glomerulofiltration rate was preserved in comparison to the progressive deterioration in both kidney damage and kidney function in a matched cohort of patients receiving best medical care [71].

\section{Medication}

Obesity and its related diseases are associated with an increased prescriptive drug use when compared to the normal weight population. The number of prescribed drugs decreases from 6.93 before to 4.88 within the 6 months after surgery [72] (Evidence level 3a). However, $44.8 \%$ of patients who had no pharmaceutical treatment prior to surgery had at least one prescribed drug 6 years after surgery which was even higher when compared to a conventionally treated control group [73].

\section{Conclusion}

The clinician's armamentarium against obesity and T2DM is improving through the use of specific dietary modifications, novel medical devices, pharmacotherapy and surgery. Lifestyle interventions combined with pharmacotherapy lead to a long-term weight loss of 5-10\%. This weight loss in obese patients with T2DM seems to be inadequate to reduce mortality. On the other hand, weight loss of 5-10\% lead to clinically meaningful improvements in glycated haemoglobin levels and better control of diabetes. Other benefits include reductions in sleep apnea, depression, number of medication as well as improvements in quality of life, physical and sexual functioning. Bariatric surgery leads to clinically significant and long-term maintained body weight loss and reduction in obesity related morbidity and mortality. Complication rates and surgical mortality have decreased over the last decades. Reducing body weight and improving the manifold comorbidities may improve the economic burden of obesity. It does not appear sensible anymore to subject all patients to intensive lifestyle interventions in the hope to improve mortality. The same level of evidence for surgery is still awaited, but it appears that a more informed patient selection is required for all modalities of treatment. If this can be combined with honest expectation setting then worthwhile long term benefits may be more readily achieved.

\section{References}

1. Rodgers RJ, Tschöp MH, Wilding JP (2012) Anti-obesity drugs: past, present and future. Dis Model Mech 5: 621-626.

2. Haslam DW, James WP (2005) Obesity. Lancet 366: 1197-1209.

3. Centers for Disease Control and Prevention (CDC) Overweight and Obesity: causes and consequences.

4. Papamargaritis DK, Pournaras DJ, le Roux CW. (2011) Techniques, assessment and effectiveness of bariatric surgery in combating obesity. Open Access Surgery 3: 123-136 
5. Aasheim ET, Aylwin SJB, Radhakrishnan ST, Sood AS, Jovanovic A, et al. (2011) Assessment of obesity beyond body mass index to determine benefit of treatment. Clinical Obesity 1:77-84.

6. Ryan DH, Espeland MA, Foster GD, Haffner SM, Hubbard VS, et al. (2003) Look AHEAD (Action for Health in Diabetes): design and methods for a clinical trial of weight loss for the prevention of cardiovascular disease in type 2 diabetes. Control Clin Trials 24: 610-628.

7. Kuna ST, Reboussin DM, Borradaile KE, Sanders MH, Millman RP, et al. (2013) Long-term effect of weight loss on obstructive sleep apnea severity in obese patients with type 2 diabetes. Sleep 36: 641-649A.

8. The Look AHEAD Research Group. Cardiovascular Effects of Intensive Lifestyle Intervention in Type 2 Diabetes. The New England journal of medicine

9. Torgerson JS, Hauptman J, Boldrin MN, Sjöström L (2004) XENical in the prevention of diabetes in obese subjects (XENDOS) study: a randomized study of orlistat as an adjunct to lifestyle changes for the prevention of type 2 diabetes in obese patients. Diabetes Care 27: 155-161.

10. Schouten R, Rijs CS, Bouvy ND, Hameeteman W, Koek GH, et al. (2010) A multicenter, randomized efficacy study of the EndoBarrier Gastrointestinal Line for presurgical weight loss prior to bariatric surgery. Ann Surg 251: 236-243.

11. Gersin KS, Rothstein RI, Rosenthal RJ, Stefanidis D, Deal SE, et al. (2010) Open-label, sham-controlled trial of an endoscopic duodenojejunal bypass liner for preoperative weight loss in bariatric surgery candidates. Gastrointes Endosc 71: 976-982.

12. Look AHEAD Research Group, Wing RR (2010) Long-term effects of a lifestyle intervention on weight and cardiovascular risk factors in individuals with type 2 diabetes mellitus: four-year results of the Look AHEAD trial. Arch Intern Med 170: $1566-1575$

13. James WP, Caterson ID, Coutinho W, Finer N, Gaal LFV, et al. (2010) Effect of sibutramine on cardiovascular outcomes in overweight and obese subjects. The New England journal of medicine:905-917.

14. Gregg EW, Chen H, Wagenknecht LE, Clark JM, Delahanty LM, et al. (2012) Association of an intensive lifestyle intervention with remission of type 2 diabetes. JAMA 308: 2489-2496.

15. Drucker DJ, Buse JB, Taylor K, Kendall DM, Trautmann M, et al. (2008) Exenatide once weekly versus twice daily for the treatment of type 2 diabetes: a randomised, open-label, non-inferiority study. Lancet 372: 1240-1250.

16. Blevins T, Pullman J, Malloy J, Yan P, Taylor K, et al. (2011) DURATION-5 exenatide once weekly resulted in greater improvements in glycemic contro compared with exenatide twice daily in patients with type 2 diabetes. J Clin Endocrinol Metab 96: 1301-1310.

17. de Moura EG, Martins BC, Lopes GS, Orso IR, de Oliveira SL, et al. (2012) Metabolic improvements in obese type 2 diabetes subjects implanted for 1 year with an endoscopically deployed duodenal-jejunal bypass liner. Diabetes Technol Ther 14: 183-189.

18. Escalona A, Pimentel F, Sharp A, Becerra P, Slako M, et al. (2012) Weight loss and metabolic improvement in morbidly obese subjects implanted for 1 year with an endoscopic duodenal-jejunal bypass liner. Ann Surg 255: 1080-1085.

19. Redmon JB, Bertoni AG, Connelly S, Feeney PA, Glasser SP, et al. (2010) Effect of the look AHEAD study intervention on medication use and related cost to treat cardiovascular disease risk factors in individuals with type 2 diabetes. Diabetes Care 33: 1153-1158.

20. Rejeski WJ, Ip EH, Bertoni AG, Bray GA, Evans G, et al. (2012) Lifestyle change and mobility in obese adults with type 2 diabetes. $\mathrm{N}$ Engl J Med 366: 1209-1217.

21. Foy CG, Lewis CE, Hairston KG, Miller GD, Lang W, et al. (2011) Intensive lifestyle intervention improves physical function among obese adults with knee pain: findings from the Look AHEAD trial. Obesity (Silver Spring) 19: 83-93.

22. Rosen RC, Wing RR, Schneider S, Wadden TA, Foster GD, et al. (2009) Erectile dysfunction in type 2 diabetic men: relationship to exercise fitness and cardiovascular risk factors in the Look AHEAD trial. J Sex Med 6: 1414-1422.

23. Wing RR, Bond DS, Gendrano IN 3rd, Wadden T, Bahnson J, et al. (2013) Effect of Intensive Lifestyle Intervention on Sexual Dysfunction in Women With Type 2 Diabetes: Results from an ancillary Look AHEAD study. Diabetes Care

24. Faulconbridge LF, Wadden TA, Rubin RR, Wing RR, Walkup MP, et al. (2012) One-year changes in symptoms of depression and weight in overweight/obese individuals with type 2 diabetes in the Look AHEAD study. Obesity (Silver Spring) 20: 783-793.
5. Williamson DA, Rejeski J, Lang W, Van Dorsten B, Fabricatore AN, et al. (2009) Impact of a weight management program on health-related quality of life in overweight adults with type 2 diabetes. Arch Intern Med 169: 163-171.

26. Stewart TM, Bachand AR, Han H, Ryan DH, Bray GA, et al. (2011) Body image changes associated with participation in an intensive lifestyle weight loss intervention. Obesity (Silver Spring) 19: 1290-1295.

27. De Groot NL, Burgerhart JS, Van De Meeberg PC, de Vries DR, Smout AJ, et al. (2009) Systematic review: the effects of conservative and surgical treatment for obesity on gastro-oesophageal reflux disease. Aliment Pharmacol Ther 30 1091-1102.

28. Austin GL, Thiny MT, Westman EC, Yancy WS Jr, Shaheen NJ (2006) A very low-carbohydrate diet improves gastroesophageal reflux and its symptoms. Dig Dis Sci 51: 1307-1312.

29. Mathus-Vliegen LM, Tytgat GN (1996) Twenty-four-hour pH measurements in morbid obesity: effects of massive overweight, weight loss and gastric distension. Eur J Gastroenterol Hepatol 8: 635-640.

30. Frederiksen SG, Johansson J, Johnsson F, Hedenbro J (2000) Neither lowcalorie diet nor vertical banded gastroplasty influence gastro-oesophageal reflux in morbidly obese patients. Eur J Surg 166: 296-300.

31. Navaneethan SD, Yehnert H, Moustarah F, Schreiber MJ, Schauer PR, et al. (2009) Weight loss interventions in chronic kidney disease: a systematic review and meta-analysis. Clin J Am Soc Nephrol 4: 1565-1574.

32. Lazo M, Solga SF, Horska A, Bonekamp S, Diehl AM, et al. (2010) Effect of 12-month intensive lifestyle intervention on hepatic steatosis in adults with type 2 diabetes. Diabetes Care 33: 2156-2163.

33. Pournaras DJ, Aasheim ET, Søvik TT, Andrews R, Mahon D, et al. (2012) Effect of the definition of type II diabetes remission in the evaluation of bariatric surgery for metabolic disorders. Br J Surg 99: 100-103.

34. Buchwald H, Oien DM (2013) Metabolic/bariatric surgery worldwide 2011 Obesity surgery: 427-436.

35. Smith MD, Patterson E, Wahed AS, Belle SH, Berk PD, et al. (2011) Thirty-day mortality after bariatric surgery: independently adjudicated causes of death in the longitudinal assessment of bariatric surgery. Obes Surg 21: 1687-1692.

36. Birkmeyer NJ, Dimick JB, Share D, Hawasli A, English WJ, et al. (2010) Hospital complication rates with bariatric surgery in Michigan. JAMA 304: 435-442.

37. DeMaria EJ, Murr M, Byrne TK, Blackstone R, Grant JP, et al. (2007) Validation of the obesity surgery mortality risk score in a multicenter study proves it stratifies mortality risk in patients undergoing gastric bypass for morbid obesity. Annals of surgery 246: $578-582$; discussion $583-574$

38. Neff KJ, Olbers T, le Roux CW (2013) Bariatric surgery: the challenges with candidate selection, individualizing treatment and clinical outcomes. BMC Med 11: 8

39. Greenburg DL, Lettieri CJ, Eliasson AH (2009) Effects of surgical weight loss on measures of obstructive sleep apnea: a meta-analysis. Am J Med 122: 535542

40. Pories WJ (2008) Bariatric surgery: risks and rewards. J Clin Endocrinol Metab 93: S89-96.

41. Sjöström L, Narbro K, Sjöström CD, Karason K, Larsson B, et al. (2007) Effects of bariatric surgery on mortality in Swedish obese subjects. N Engl J Med 357 741-752.

42. Angrisani L, Lorenzo M, Borrelli V (2007) Laparoscopic adjustable gastric banding versus Roux-en-Y gastric bypass: 5 -year results of a prospective randomized trial. Surg Obes Relat Dis 3: 127-132.

43. Himpens J, Dapri G, Cadière GB (2006) A prospective randomized study between laparoscopic gastric banding and laparoscopic isolated sleeve gastrectomy: results after 1 and 3 years. Obes Surg 16: 1450-1456.

44. Keidar A, Hershkop KJ, Marko L, Schweiger C, Hecht L, et al. (2013) Rouxen-Y gastric bypass vs sleeve gastrectomy for obese patients with type 2 diabetes: a randomised trial. Diabetologia 56: 1914-1918.

45. Sjöström L, Lindroos AK, Peltonen M, Torgerson J, Bouchard C, et al. (2004) Lifestyle, diabetes, and cardiovascular risk factors 10 years after bariatric surgery. N Engl J Med 351: 2683-2693.

46. Karason K, Wikstrand J, Sjöström L, Wendelhag I (1999) Weight loss and progression of early atherosclerosis in the carotid artery: a four-year controlled study of obese subjects. Int J Obes Relat Metab Disord 23: 948-956. 
Citation: Bächler T, Papamargaritis D, Bueter M, le Roux CW (2013) Treatment of Morbid Obesity: Intensive Lifestyle Intervention vs. Bariatric Surgery. Surgery Curr Res 3: 147. doi:10.4172/2161-1076.1000147

47. Sjöström L, Peltonen M, Jacobson P, Sjöström CD, Karason K, et al. (2012) Bariatric surgery and long-term cardiovascular events. JAMA 307: 56-65.

48. Mingrone G, Panunzi S, De Gaetano A, Guidone C, laconelli A, et al. (2012) Bariatric surgery versus conventional medical therapy for type 2 diabetes. N Engl J Med 366: 1577-1585.

49. Schauer PR, Kashyap SR, Wolski K, Brethauer SA, Kirwan JP, et al. (2012) Bariatric surgery versus intensive medical therapy in obese patients with diabetes. N Engl J Med 366: 1567-1576.

50. Buse JB, Caprio S, Cefalu WT, Ceriello A, Del Prato S, et al. (2009) How do we define cure of diabetes? Diabetes Care 32: 2133-2135.

51. Boza C, Muñoz R, Salinas J, Gamboa C, Klaassen J, et al. (2011) Safety and efficacy of Roux-en-Y gastric bypass to treat type 2 diabetes mellitus in nonseverely obese patients. Obes Surg 21: 1330-1336.

52. Buchwald H, Estok R, Fahrbach K, Banel D, Jensen MD, et al. (2009) Weight and type 2 diabetes after bariatric surgery: systematic review and metaanalysis. Am J Med 122: 248-256.

53. Neovius M, Narbro K, Keating C, Peltonen M, Sjöholm K, et al. (2012) Health care use during 20 years following bariatric surgery. JAMA 308: 1132-1141.

54. Dixon J (2012) Obesity: health economics of bariatric surgery--benefit versus cost. Nat Rev Endocrinol 8: 632-633.

55. Kolotkin RL, Crosby RD, Pendleton R, Strong M, Gress RE, et al. (2003) Health-related quality of life in patients seeking gastric bypass surgery vs nontreatment-seeking controls. Obes Surg 13: 371-377.

56. Adams TD, Pendleton RC, Strong MB, Kolotkin RL, Walker JM, et al. (2010) Health outcomes of gastric bypass patients compared to nonsurgical, nonintervened severely obese. Obesity (Silver Spring) 18: 121-130.

57. Vincent HK, Heywood K, Connelly J, Hurley RW (2012) Obesity and weight loss in the treatment and prevention of osteoarthritis. PM R 4: S59-67.

58. Peltonen M, Lindroos AK, Torgerson JS (2003) Musculoskeletal pain in the obese: a comparison with a general population and long-term changes after conventional and surgical obesity treatment. Pain 104: 549-557.

59. Wadden TA, Sarwer DB, Fabricatore AN, Jones L, Stack R, et al. (2007) Psychosocial and behavioral status of patients undergoing bariatric surgery: what to expect before and after surgery. Med Clin North Am 91: 451-469, xi-xii.

60. Gosman GG, King WC, Schrope B, Steffen KJ, Strain GW, et al. (2010) Reproductive health of women electing bariatric surgery. Fertil Steril 94: 14261431

61. Patel JA, Colella JJ, Esaka E, Patel NA, Thomas RL (2007) Improvement in infertility and pregnancy outcomes after weight loss surgery. Med Clin North Am 91: 515-528, xiii.

62. Karlsson J, Taft C, Rydén A, Sjöström L, Sullivan M (2007) Ten-year trends in health-related quality of life after surgical and conventional treatment for severe obesity: the SOS intervention study. Int J Obes (Lond) 31: 1248-1261.

63. Pull CB, Aguayo GA (2011) Assessment of body-image perception and attitudes in obesity. Curr Opin Psychiatry 24: 41-48.

64. Adami GF, Meneghelli A, Bressani A, Scopinaro N (1999) Body image in obese patients before and after stable weight reduction following bariatric surgery. $J$ Psychosom Res 46: 275-281.

65. Dent J, El-Serag HB, Wallander MA, Johansson S (2005) Epidemiology of gastro-oesophageal reflux disease: a systematic review. Gut 54: 710-717.

66. Himpens J, Dobbeleir J, Peeters G (2010) Long-term results of laparoscopic sleeve gastrectomy for obesity. Ann Surg 252: 319-324.

67. Patterson EJ, Davis DG, Khajanchee Y, Swanström LL (2003) Comparison of objective outcomes following laparoscopic Nissen fundoplication versus laparoscopic gastric bypass in the morbidly obese with heartburn. Surg Endosc 17: 1561-1565.

68. Bueter M, Ashrafian H, Frankel AH, Tam FW, Unwin RJ, et al. (2011) Sodium and water handling after gastric bypass surgery in a rat model. Surg Obes Relat Dis $7: 68-73$.

69. Hallersund $P$, Sjöström L, Olbers T, Lönroth $H$, Jacobson $P$, et al. (2012) Gastric bypass surgery is followed by lowered blood pressure and increased diuresis - long term results from the Swedish Obese Subjects (SOS) study. PLoS One 7: e49696.

70. Bueter M, Dubb SS, Gill A, Joannou L, Ahmed A, et al. (2010) Renal cytokines improve early after bariatric surgery. Br J Surg 97: 1838-1844.

71. Miras AD, Chuah LL, Lascaratos G, Faruq S, Mohite AA et al. (2012) Bariatric surgery does not exacerbate and may be beneficial for the microvascular complications of type 2 diabetes. Diabetes Care 35: e81.

72. Iaconelli A, Panunzi S, De Gaetano A, Manco M, Guidone C, et al. (2011) Effects of bilio-pancreatic diversion on diabetic complications: a 10-year followup. Diabetes Care 34: 561-567.

73. Hodo DM, Waller JL, Martindale RG, Fick DM (2008) Medication use after bariatric surgery in a managed care cohort. Surg Obes Relat Dis 4: 601-607.

74. Narbro K, Agren G, Jonsson E, Näslund I, Sjöström L, et al. (2002) Pharmaceutical costs in obese individuals: comparison with a randomly selected population sample and long-term changes after conventional and surgical treatment: the SOS intervention study. Archives of internal medicine 162: $2061-2069$ 